\title{
The rising tide: migration as a response to loss and damage from sea level rise in vulnerable communities
}

\author{
Erin Roberts* \\ Department of Geography, \\ King's College London, \\ Strand Campus, \\ Strand, London WC2R 2LS, UK \\ Email: roberts.erin@gmail.com \\ Email: erin.roberts@kcl.ac.uk \\ *Corresponding author
}

\section{Stephanie Andrei}

International Centre for Climate Change and Development, 98 Park Road, Baridhara 1212,

Dhaka 1212, Bangladesh

Email: andrei.stephanie@gmail.com

\begin{abstract}
As climate change impacts worsen, losses and damages incurred in both developing and developed countries will continue to increase. While enhancing mitigation and adaptation efforts will influence the level of loss and damage avoided in the future, historical emissions have 'locked in' a certain level of climate change, making some residual losses and damages inevitable. Loss and damage from slow onset processes like sea level rise will ultimately require some communities and, in some cases, entire countries to relocate. Through examples from Kiribati and Alaska this paper will highlight the complexity involved in migrating and relocating and recommend interventions for easing the resettlement process.
\end{abstract}

Keywords: loss and damage; slow onset processes; sea level rise; climate change; migration; relocation; adaptation; Alaska; Small Island Developing States; SIDS; Kiribati; non-economic losses; culture.

Reference to this paper should be made as follows: Roberts, E. and Andrei, S. (2015) 'The rising tide: migration as a response to loss and damage from sea level rise in vulnerable communities', Int. J. Global Warming, Vol. 8, No. 2, pp. 258-273.

Biographical notes: Erin Roberts is a $\mathrm{PhD}$ student at in the Department of Geography King's College London and a visiting researcher at the International Centre for Climate Change and Development. Her research interests include development, vulnerability, climate change adaptation and the limits to adaptation, transformation and approaches to address loss and damage in developing countries.

Stephanie Andrei is a researcher at the International Centre for Climate Change and Development and has completed her Master's in International Migration and Public Policy at the London School of Economics and Political Science. 
Her research interests include environmentally-induced migration, analysing the migration-development nexus, planned migration, approaches for addressing loss and damage and livelihood security.

\section{Introduction}

In 2010, the president of the Maldives, Mohammed Nasheed, held a cabinet meeting six metres under the surface of the Indian Ocean to call attention to sea level rise (SLR) and its projected impacts on Small Island Developing States (SIDS) (Ramesh, 2009). SLR is one of the most significant impacts of climate change, with repercussions for both developing and developed countries. The latest scientific findings conclude that it is very likely that global mean SLR was greater than $3.2 \mathrm{~mm}$ per year between 1993 and 2010 (Church et al., 2013). Sea levels will very likely continue to rise throughout the rest of the 21st century at levels exceeding those observed during the last three decades due to processes like thermal expansion of oceans and glacial melt (Ibid). Depending on emission pathways global mean SLR is likely to be between $0.26 \mathrm{~m}$ and $0.98 \mathrm{~m}$ for the period 2081 to 2100 compared to the period 1985 to 2005 (Ibid). Though low-lying coastal areas comprise only $2 \%$ of the world's land mass, they are home to $10 \%$ of the world's population and $13 \%$ of its urban population (Wong et al., 2014). Even at the lowend of the spectrum, SLR will have severe impacts on those living close to the coast (Nicholls and Cazenave, 2010; FitzGerald et al., 2008) affecting livelihoods, altering well-being and forcing some households and communities to migrate or relocate. Climate change impacts like SLR are already among the many factors driving migration but as the impacts become more severe and less predictable, the rate of migration primarily driven by climate change is likely to increase (Bogardi and Warner, 2008; Tacoli, 2009; Newland, 2011). Uncertainty about future SLR and the fact that climate change is but one of many drivers of migration makes it difficult to pinpoint the exact levels of human mobility that will result from rising sea levels (Byravan and Rajan, 2010). Dasgupta et al. (2007) maintain that tens of millions of people will be displaced by SLR by the end of the century while other estimates vary from 200 million people (Brown, 2008; Nicholls et al., 2011) to up to one billion (Byravan and Rajan, 2010).

The impacts of SLR is already forcing many communities and in some cases entire countries, to contemplate relocation. Among those countries most at risk from SLR are the SIDS, particularly the atoll states in the Pacific Ocean and the Indian Ocean, whose vulnerability has been well documented (Pelling and Uitto, 2001). A number of factors render atolls vulnerable to climate change including their small size, isolation, high population densities, limited supplies of fresh water and exposure to the impacts of storm surges and coastal erosion (Barnett and Adger, 2003). Kiribati, a low-lying island state in the Pacific Ocean, is among the states at risk of being entirely inundated by the end of the century (Boncour and Burson, 2010). Climate change is already exacerbating both socio-economic and environmental problems in Kiribati and is a push factor in increased migration to the main island thereby increasing urbanisation and putting additional stress on both the economy and natural resources (Locke, 2009). By 2050 it is estimated that economic loss and damage could reach $34 \%$ of GDP in Kiribati (World Bank, 2011b). It is likely that the citizens of Kiribati, or I-Kiribati, will eventually need to permanently re-settle in other states due to the impacts of SLR and 
salinisation (Watters, 2008). The Government of Kiribati has already begun long-term planning for relocation with a comprehensive adaptation strategy (World Bank 2011a, 2011b).

Thousands of kilometres away in Alaska, SLR, coastal erosion and permafrost thaw are threatening several indigenous communities living along the state's $53 \mathrm{~km}$ long coastline making travel difficult, damaging infrastructure, threatening ecosystems, reducing supplies of fresh water and negatively impacting both health and well-being (Alessa et al., 2008; Larsen et al., 2008). Some communities have already begun taking action to relocate. Such relocation efforts are not without their challenges however. Migration inland will have both cultural and social impacts (Ford, 2009; Crump, 2008). For instance, individuals moving further inland will likely have to adopt new hunting and fishing practices due to unpredictable weather and the changing habits of marine mammals that are dependent on sea ice for their habitat. Climate change impacts on sea ice make travel more difficult which threatens food security and renders traditional and indigenous knowledge obsolete (Hinzman et al., 2005).

Permanent relocation will also result in a loss of a sense of place and belonging. Sense of place is a term used to refer to "the subjective meaning of place, attachment to place, place identity, belonging, awareness and knowledge of place play are important factors" (Cresswell, 2004 in Amundsen, 2013). The physical aspects of a place such as the natural surroundings, climate and weather are important factors in the identification with a particular place (Rose, 1005 in Amundsen, 2013). Thus, even communities who do not relocate will experience a loss of sense of place. That said, there are many communities who will not have a choice as losses and damages from climate change impacts make relocation a necessity. This paper will explore how climate change is affecting lives and livelihoods in vulnerable communities in two different contexts, forcing many citizens and entire communities to migrate or relocate, in a least developed country (Kiribati) as well as a developed country (Alaska) using existing literature. It will conclude that efforts to facilitate planned relocation will be more successful if citizens are engaged in the process and policies are in place to prevent the degradation of standards of living. However, the paper will also demonstrate that some losses and damages incurred in the relocation process - such as the social and cultural impacts associated with a loss of place - will be difficult to address.

\section{Loss and damage from slow onset processes}

\subsection{Defining loss and damage}

Loss and damage from climate change impacts is a concept that has its genesis in the global climate change negotiations under the United Nations Framework Convention on Climate Change (UNFCCC). There is as yet no agreed up on definition of loss and damage. However, one working definition describes loss and damage as the impacts of climate change that individuals and communities can neither cope with nor adapt to (Warner et al., 2012). While the meaning of loss and damage continues to be debated, losses and damages are being incurred at the local level by households and communities around the world. In that sense, loss and damage can be perceived as a failure of mitigation and adaptation efforts to prevent all of the impacts of climate change. Loss and damage can also be seen as a spanning spectrum, beginning with those impacts that can 
be avoided through mitigation and adaptation efforts, progressing to those impacts that have not been avoided ('unavoided') through adequate mitigation and adaptation efforts and finally to those impacts that cannot be avoided ('unavoidable') such as the impacts of SLR (Verheyen, 2012).

Loss and damage that is not avoided is categorised as either economic or non-economic loss and damage. Economic loss and damage - including loss of gross domestic product (GDP) and loss and/or damage to physical assets - is accounted for in formal accounting processes (Morrissey and Oliver-Smith, 2013). Non-economic losses such as the loss of lives, traditional or indigenous knowledge, ecosystem services and cultural, social and psychological impacts, are not accounted for in formal accounting process and therefore are more difficult to both measure and address (Ibid). The cultural impacts of climate change can be especially profound as culture is the foundation upon which communities are built and through which they organise (Ibid). Communities play an important role in developing a set of common values and identity that, in turn, helps bring individuals together and enhances resilience (Ibid). Since culture and community are often rooted in physical places, permanent relocation threatens not only individuals' sense of identity but also communities' ability to organise and cope with difficult circumstances (Adger et al., 2012).

Slow onset processes like SLR could contribute to 'large-scale population movement' for many communities across the globe (Warner et al., 2013). While migration has long been employed as a response to environmental change and as a livelihood strategy, research indicates that the impacts of both climate variability and climate change are increasingly influencing human mobility. The human mobility patterns resulting from changing climatic conditions range from voluntary and involuntary migration (internally or across borders) to displacement and planned relocation (Ibid). Decisions to migrate are generally made at the household level with the intention of improving household income (Foresight, 2011). However, not all forms of human mobility can be considered successful tools to address climate change. For instance, whereas seasonal labour migration may improve the economic prospects of a household and reduce its vulnerability, displacement could be symbolic of a failure of adaptation (Frankhauser, 2009) and could exacerbate vulnerability. In addition, many of those most exposed to the impacts of climate change, such as individuals and households who rely on natural resources and ecosystem services for their livelihoods, are often least able to move (Betts, 2010). Yet this is not the only way individuals' get left behind. Increasingly research has suggested that cultural ties to the land have made individuals willingly stay behind (McAdam and Loughry, 2009) - a right all citizens have.

\subsection{SLR in Kiribati}

Kiribati is made up of 33 coral islands that are on average 430 to 450 metres wide and three to four metres above sea level (Government of Kiribati, 2007). The population of Kiribati is estimated at 106,000 only $18 \%$ of which is permanently employed (World Bank, 2011b). Since the majority of Kiribati's territory low-lying coral atolls, SLR, drought, salinisation and storm surges threaten the country's infrastructure, arable land and underground fresh water supplies (Ibid). The capital of Kiribati is South Tarawa, a string of islets, which is under increasing population pressure due to increasing rates of urbanisation. The population density of the larger islands will increase as SLR continues to inundate smaller nearby islands. Some villages, such as Tebunginako in Abaiang, 
located in the Northern Gilbert Islands, have already been forced to relocate due to SLR, erosion and salinisation (Langan, 2013). It is predicted that by 2050 up to $80 \%$ of the land on the island of Buariki and $50 \%$ of the land on Bikenibeu may be completely inundated (World Bank, 2011a). Yet given the nature of atoll reef platforms, the type of changes as well as magnitude of change will vary between islands. Some atoll islands in the Pacific Ocean may very well increase in size, in some cases by up to $30 \%$ (Webb and Kench, 2010). While for some islands, the impact of SLR may not be an imminent threat, salinisation is a grave concern for many, if not all I-Kiribati. A combination of changing rainfall patterns, increased temperatures and SLR is simultaneously decreasing supplies of groundwater while increasing salinity levels. This has led to a severe shortage of freshwater in Tarawa which has significant repercussions for human health and well-being as well as agricultural productivity (World Bank, 2011b).

The magnitude loss and damage likely to be incurred by SIDS like Kiribati as a result of climate change is 'enormous' in relation to the size of their economies (Anthoff et al., 2010). As a country with a GDP of 151 million USD, making plans to construct a series of sea walls and mangroves, that will likely cost billions, is not a feasible option for Kiribati (Wyett, 2014). That said, Kiribati has developed a pro-active adaptation strategy. At present, the country is in its third phase of the Kiribati Adaptation Program which will be completed in 2016. The program aims to build resilience to climate change through strategies that include enhanced water management, protection against coastal erosion and national and local policies to strengthen capacity and support for managing, monitoring and evaluating progress (Government of Kiribati, 2007; World Bank, 2011a). Although these efforts are small in scale, the program could delay the urgency of relocation efforts.

\subsection{SLR, soil erosion and permafrost melt in Alaska}

Across the globe in an entirely different geographic context climate change is also inflicting significant loss and damage in some communities in the Arctic. According to some sources the, impacts of climate change will be felt 'the earliest and the strongest' in the Arctic (Serreze and Francis, 2006). Models have predicted that by the end of the 21st century, the Arctic could warm between 5 and $7^{\circ} \mathrm{C}$, twice the predicted rise of global mean temperatures (Kattsov and Källén, 2005). The Intergovernmental Panel on Climate Change's Fifth Assessment Report, predicts that under a high emissions scenario it is likely that the Arctic Ocean will be ice-free for parts of the summer before the end of this century (Larsen et al., 2014). Changing weather patterns, a thinning and reduction in the extent of sea and river ice, thawing permafrost and changes in the abundance and composition of both flora and fauna in the region have significant consequences for indigenous communities in the Arctic (Forbes, 2011), the impacts of which are cascading. Permafrost melt is causing damage to infrastructure as well as water and sewage systems (Bronen, 2013). In addition, sea ice, which provides transportation routes to link communities and provide access to hunting grounds, is thinning, which increases the danger associated with travel (Ibid). This has implications for food security, the tourism industry and will likely also impact the physical well-being of communities (Larsen et al., 2014) as well as their connection to the land.

A close relationship with the environment and the significant role that natural resources play in contributing to physical, social and cultural well-being renders indigenous peoples in the Artic particularly vulnerable to the impacts of climate change 
(Nuttall et al., 2005; Parkinson and Butler, 2005; Cochran et al., 2013). As the majority of households practice subsistence harvesting (AHDR, 2004), the decline in the predictability of weather patterns could render Artic communities 'strangers in their own land' (Berkes, 2002). Political and economic pressures have had significant changes on communities in the North. The establishment of permanent settlements for indigenous Alaskans rendered much traditional knowledge obsolete (USACE, 2009). Nomadic traditions offered indigenous peoples the flexibility to respond to changing climatic stressors - using their own observations and senses of the environment to practice subsistence agriculture and hunting (Bronen, 2013). The departure from these knowledge systems has made residents more vulnerable to the impacts of climate change (Norton, 2002). For example, even before tools were used to measure changing temperatures and sea-ice levels, residents had observed a warming climate and decreased sea-ice levels (Thorpe et al., 2002; Krupnik and Jolly, 2002). More recently however, the introduction of wages, hunting regulations, education bylaws and other public institutions has significantly changed traditional and cultural norms. This loss of traditional knowledge alongside less predictable weather and ice conditions has significantly affected residents' ability to cope with environmental change.

Even though the impacts of climate change are well documented in the Arctic, there are few resources to help these communities adapt to the imminent risk of climate change. While organisations such as the Federal Emergency Management Agency (FEMA) and the Army Corps of Engineers (ACE) are meant to help communities prepare, respond and recover from disasters and water stress, respectively, in reality, the process is reactive rather than proactive and does not necessarily cover slow onset processes such as SLR and coastal erosion (Shearer, 2012). Although more recently climate change has created a heightened sense of urgency in the state's mitigation efforts, the trend has been towards contracting private companies rather than using a bottom-up approach (Gunewardena et al., 2008).

\section{Migration approaches to deal with SLR}

\subsection{Facilitated migration in Kiribati}

In an emotional plea on the final day of COP 15 in Copenhagen, the President of Kiribati stated that due to the lack of progress in the global climate negotiations, his country would have to begin planning for the relocation of its citizenry (Radio New Zealand International, 2009). In the years since that plea was made the entire population of the village of Tebunginako on the island of Abaiang has had to relocate due to climate impacts that rendered the island uninhabitable (Langan, 2013). Tebunginako has become a 'barometer' for future expected losses (Ibid). In response to future predicted climate change scenarios, the Government of Kiribati has already developed a long-term strategy on relocation, with the aim of allowing citizens who wish to do so to migrate with dignity. In the action plan for operationalising the strategy the government makes it clear that migration should be facilitated and assistance should be available for those who wish to migrate in the coming years (Government of Kiribati, 2013). Training will be provided for individuals who wish to migrate to countries such as Australia and New Zealand since they will likely need to explore different livelihood strategies (Ibid). The relocation strategy includes technical and vocational programs to prepare young people for the 
international labour market as well as programs to improve the English skills of primary school teachers (Strategic National Policy Unit, Office of the Beretitenti, Kiribati, 2012). The programs are targeted at young people aged 16 to 24 (Ibid) with the aim of creating expatriate communities of I-Kiribati who will be able to support future migrants (Kiribati Climate Change, n.d.). If the entire population is to relocate in the coming decades these efforts will need to be scaled up. At present New Zealand admits only 75 I-Kiribati per year many of whom are unable to meet the requirements of permanent residency (Bedford and Bedford, 2010).

The Government of Kiribati is also taking measures to protect I-Kiribati in the event of the complete inundation of its territory. One of the goals of the second phase of the Kiribati Adaptation Program (KAP-II), which began in 2006 and ended in 2011, was to demonstrate that relocation of the entire population was not the only viable tool to respond to climate change and in fact cost-effective adaptation options were also available (World Bank, 2011a). In response to a reduction in the amount of arable land due to salinisation and SLR, the Government of Kiribati purchased 6,000 acres of land on Vanua Levu, Fiji's second largest island, to improve food security (Government of Fiji, 2014). These efforts will delay the need for relocation but given the rate of global emissions, relocation of the entire population of Kiribati appears to be an eventuality. With the complete loss of territory will come questions of what it means to be a sovereign state. De facto statelessness, which would be the case if the entire country of Kiribati becomes submerged, does not necessarily dissolve the functions of the government to govern over its citizens. Otherwise understood as 'governments in exile,' Crawford (2006) and Kälin (2010) have noted that loss of territory may not denote loss of sovereignty and statehood. From this perspective, citizens can retain their citizenship as IKiribati in whatever country they relocate to but relocation will nonetheless have tremendous impacts on the culture, traditions and language of these citizens.

\subsection{Relocation efforts in Alaska}

Four communities in Alaska are faced with the imminent need for relocation and 'dozens of others are at risk' due primarily to the impacts of a changing climate, most notably coastal erosion and permafrost thaw [Bronen, (2013), p.2]. Although communities have been aware of the impending threat of climate change for some time now, efforts to relocate villages have been delayed for a number of reasons, including the costs of relocation and the fact that there is no institutional system in place to support relocation (Ibid). As the impacts of climate change increase, the costs and complexities associated with relocation are increasing. For instance, the estimated costs of relocation for the village of Shishmaref, located on Sarichef Island, about $50 \mathrm{~km}$ south of the Arctic Circle, was significantly lower in the 1970s when the government was first made aware of the eventual need to relocate compared to today's estimate of between 100 and 200 million USD (Marino, 2009). It is also important to ensure that relocation efforts begin before the impacts of climate change worsen so that citizens can choose their new location and develop a relocation plan that minimises the losses and damages involved in moving an entire community from the place to which they are connected.

At present, there is no organised institutional system in place to support the relocation efforts of Alaskan communities and each of the four communities facing the need for imminent relocation are involved in 'ad-hoc processes' (Bronen, 2013). This places a large burden on communities in terms of gathering sufficient resources and capacity. A 
report by the US Government Accountability Office (GAO) in 2009 found that of the four villages requiring immediate relocation, only one had identified a site for resettlement that was deemed 'safe, sustainable and desirable' by the villagers and various levels of government (GAO, 2009). However, in 2006 it was predicted that the villages of Kivalina, Newtok and Shishmaref have less than 15 years to relocate and the cost of relocating each community would be approximately 80 to 200 million USD (Corps House Report, 2004 in GAO, 2009).

Of all the communities in Alaska that are faced with the need for imminent relocation, the village of Newtok has made the most significant strides in its plan to relocate. Following a storm that left Newtok completely surrounded by floodwater, the village formed a planning group in 2006 through which they voted to relocate. However given the lack of capacity and resources, the village was unable to obtain federal funding to follow through with these plans (GAO, 2009). Without federal assistance, villagers will need to either relocate on their own or wait for the emergency relief that would follow a disaster and result in less optimal, unplanned relocation. Additionally, unlike labour migrants that prefer to move to cities to supplement or replace their income from traditional livelihoods, members of the Alaskan communities of Kivalina, Koyukuk, Newtok, Shaktoolik and Shishmaref have indicated a preference for their village to be relocated to an uninhabited area (Schweitzer and Marino, 2006).

The paradox of Alaska is that although federal funding would be made available following a large-scale disaster that would inevitably be more expensive, funding to respond to slow onset processes such as SLR is relatively non-existent (GAO, 2009). It should therefore come as no surprise that villagers in communities such as Shishmaref have attempted to 'consciously become the face of climate change' (Marino, 2009). Some communities have utilised media outlets to raise awareness of the challenges they face in relocating and/or developed websites as platforms to raise funds relocation (Ibid). These strategies may be a means by which to regain control for planning procedures since the communities are often not involved in this process.

\section{The way forward}

The first line of defence against loss and damage is mitigation. Reducing greenhouse gas (GHG) levels in the atmosphere will slow SLR, reduce coastal flooding and allow more time for the development and implementation of adaptation and migration strategies (Nicholls and Tol, 2006). Stabilising climate change would also serve to slow down the rate at which ice sheets in Greenland and Antarctica melt (Ibid) which together contain enough water to cause the oceans to rise by $70 \mathrm{~cm}$ (Dasgupta et al., 2007). However, even if GHG emissions cease, most impacts of climate change - like SLR - will continue for centuries to come (Collins et al., 2013). Thus, more needs to be understood about how climate change will influence population flows to inform policymaking at the local, national and international levels (Tacoli, 2009). Part of the complexity of the climatemigration nexus lies in the fact that there are multiple drivers of migration and different ways which human mobility is employed to respond to climate change. Unpacking this complex relationship will help policymakers better understand how policies can support individuals, households and communities to remain where they are where possible and migrate or relocate with dignity where not. 


\subsection{Addressing non-economic losses}

A sense of place is the identity derived from belonging to a place, the level of connection with people in that place and the sense of belong associated with belonging to the physical place, be it a village, town or city (Adger et al., 2009). These can, in turn, be a contributing factor to an individual or community's quality of life (Ibid). While 'identities' are likely to change between generations as well as within an individiual's lifetime, drawing attention to this issue is important as it demonstrates the sensitivity that is involved when speaking about migration and relocation. These symbolic connections citizens have to their country can neither be measured nor economically quantified and as a result, are often disregarded in measures of loss due to climatic events (Morrissey and Oliver-Smith, 2013). Yet cultural elements are fundamental as they dictate how communities organise themselves to cope with various stressors (Ibid). Thus, while assessing non-economic losses is challenging, it is essential that tools be developed to better understand these losses so that they can be addressed. Being aware of the different value systems and cultural practices is a step forward to helping build resilience for communities that are likely to suffer increased losses and damages, such as those in Alaska and Kiribati.

\subsection{Facilitate migration with dignity}

In the coming years the impacts of SLR - among other climate change impacts - will necessitate a greater focus on climate related migration. While the pursuit of mitigation and adaptation strategies is paramount to avoid loss and damage, residual losses and damages are unfortunately inevitable. It is estimated that between 25 and $50 \%$ of the world's coastlines cannot be protected with structural methods (Tol, 2002), which means that many SIDS and low-lying countries with long-coastlines will lose territory. This will likely necessitate some degree of migration either internally or across international borders. Where climate induced migration is internal relocated communities will need access to land, infrastructure, resources and livelihood opportunities (Campbell, 2010). Where climate induced migration is international, international institutions will need to be equipped to protect stateless individuals and assist climate induced migrants (Burson, 2010). As demonstrated by the two case studies, communities in both developed and developing countries are at risk, though they have difference capacities to respond.

Assisting climate induced migrants and facilitating relocation is complicated by legal ambiguity. Currently this subset of migrants has no place in international legal frameworks. While the debate on the term 'environmental refugees' dominated such discussions until more recently, there is consensus that neither the 1951 Convention Relating to the Status of Refugees nor its 1967 Protocol provide protection for such individuals (Black, 2001; Zetter, 2007; Biermann and Boas, 2008). Furthermore, it seems 'doubtful' that member states would agree to extend United Nations High Commissioner for Refugees (UNHCR) support from (currently) ten millions refugees to a number 'possibly 20 times larger' (Biermann and Boas, 2008). While the government of Kiribati has taken the initiative to facilitate labour migration to New Zealand and Australia, it is unclear whether this is sustainable in the long term given most of these individuals struggle to meet the requirements for permanent residency. International mechanisms must be developed to ensure the political, legal and civil rights of those rendered stateless [Byravan and Rajan, (2010), p.253]. Although citizens have a legal and moral right to 
remain in their country of origin, as it is the place that best provides for their cultural and psycho-social needs (Montreux and Barnett, 2009), it is likely that during the course of this century those living in Kiribati will be forced to relinquish that right in order to survive. Bilateral agreements, wherein one country agrees to take displaced persons from another country, may be the best way forward. The Government of Fiji has already indicated that Fiji will allow the citizens of Kiribati to re-settle within its territory. In making this commitment to Kiribati the president of Fiji stated:

\footnotetext{
"The spirit of the people of Kiribati will not be extinguished. It will live on somewhere else because a nation isn't only a physical place. A nation - and the sense of belonging that comes with it - exists in the hearts and the minds of its citizens wherever they may be." (Government of Fiji, 2014)
}

However, given that Fiji is also threatened by SLR, a global effort is needed to support those who are no longer able to live in their countries of origin due to the impacts of climate change.

To better assist those who will need to migrate or relocate within states, it is essential that the planning processes are participatory and incorporate the views and needs of those relocating. It is important that individuals remain a central part in this process. While this may seem less contentious of an issue than international migration, the case of Alaska demonstrates that government support has not been adequate to assist those communities facing imminent relocation within the state. In addition, the prioritisation of disasters has prevented organisational actors from responding in a timely fashion. Delays in relocation are costly as losses and damages will continue to accrue until the land becomes completely uninhabitable. However, if the need for relocation is identified early then funds could be diverted from budgets designated for disaster relief to support relocation efforts (Bronen, 2013) as relocation will help decrease disaster risk by reducing exposure to climate change impacts.

In order to ensure migration and relocation is facilitated with the interests of individuals and communities in mind, these processes should be conducted in a way that ensures participation of affected communities, builds resilience and improves the living standards of those affected (Warner et al., 2013). This could also help reduce loss of culture, traditions and language if communities move in tandem. If resources are available and policies are in place, the citizens of Alaska and Kiribati should have the opportunity to facilitate migration in a timely and culturally sensitive manner. However, migration should be promoted as part of a larger adaption strategy that gives individuals the greatest number of options to improve their living conditions (Warner, et al., 2013). In addition, policies will need to be in place to recognise and address non-economic losses. That said, migration should not come at the expense of development. Many residents - especially older people - will likely decide not to move. Therefore investment should continue to promote development and the provision of services in the urban areas of central and outlying islands (Bedford and Bedford, 2010).

\section{Conclusions}

Slow onset processes like SLR will result in a range of impacts that will, to a great extent, place a disproportionately large burden on poor and vulnerable groups in developing as well as developed countries. It has become clear that loss and damage will be incurred no 
matter how ambitious and widespread mitigation and adaptation strategies are, but the level of loss and damage that results depends on the choices we make today. Developing countries like Kiribati have demonstrated they are not waiting for assistance from the international community. Although citizens may lose their sense of place and identity associated with having belonged to a community that is no longer, they may not necessarily lose their sense of national identity if relocation is facilitated with dignity and with the interests of citizens in mind. Yet, strong cultural ties will likely mean many IKiribati will stay behind thereby justifying the need for continued development in the country. In contrast, in Alaska, several communities that have voted in favour of relocation have struggled to receive federal support to do so.

While some losses and damages incurred in relocating entire communities or states will not be recovered, the impacts can be minimised with adaptation policies to avoid relocation wherever possible. However, where this is not possible, the success of planned relocation and community resettlement will be enhanced if it is done in a time efficient manner and with participation of local communities. Finally, these efforts should be supported by sufficient and sustained resources to continue to improve the living standards of those most vulnerable.

\section{Acknowledgements}

The authors would like to thank Erik Wilson for his invaluable contributions to the paper as well as Cosmin Coreanda and two anonymous reviewers for their suggestions and comments.

\section{References}

Adger, N., Barnett, J., Brown, K., Marshall, N. and O'Brien, K. (2012) 'Cultural dimensions of climate change impacts and adaptation', Nature Climate Change, Vol. 3, pp.112-117.

Adger, W.N., Dessai, S., Goulden, M., Hulme, M., Lorenzoni, I., Nelson, D.R., Naess, L.O., Wolf, J. and Wreford, A. (2009) 'Are there social limits to climate change', Climate Change, Vol. 93, pp.335-354.

Alessa, L., Kliskey, A., Busey, R., Hinzman, L. and White, D. (2008) 'Freshwater vulnerabilities and resilience on the Seward Peninsula: integrating multiple dimensions of landscape change', Global Environmental Change, Vol. 18, No. 2, pp.256-70.

Amundsen, H. (2013) 'Place attachment as a driver of adaptation in coastal communities in Northern Norway', Local Environment: The International Journal of Justice and Sustainability, pp.1-20, DOI: 10.1080/13549839.2013.838751.

Anthoff, D., Nicholls, R.J. and Tol, R.S.J. (2010) 'The economic impact of substantial sea-level rise', Mitigation and Adaptation Strategies for Global Change, Vol. 15, No. 4, pp.321-335.

Arctic Human Development Report (AHDR) (2004) Arctic Human Development Report, Stefansson Arctic Institute, Akureyri.

Barnett, J. and Adger, W.N. (2003) 'Climate Dangers and Atoll Countries', Climate Change, Vol. 61, pp.321-327.

Bedford, R. and Bedford, C. (2010) 'International migration and climate change: a postcopenhagen perspective on options for Kiribati and Tuvalu', in Burson, B. (Eds.): Climate Change and Migration: South Pacific Perspectives, pp.89-134, Institute of Policy Studies, Wellington. 
Berkes, F. (2002) 'Cross-scale institutional linkages: perspectives from the bottom up', in Ostrom, E., Dietx, T., Dolak, N., Stern, P.C., Stonich, S. and Weber, E.U. (Eds.): The Drama of the Commons, pp.293-322, National Academy Press, Washington.

Betts, A. (2010) 'Survival migration: a new protection framework', Global Governance, Vol. 16, No. 3, pp.361-382.

Biermann, F. and Boas, I. (2008) 'Protecting climate refugees: the case for a global protocol', Environment Magazine [online] http://www.environmentmagazine.org/Archives/Back\%20 Issues/November-December\%202008/Biermann-Boas-full.html (accessed 30 April 2014).

Black, R. (2001) Environmental Refugees: Myth or Reality?, United Nations High Commissioner for Refugees Working Papers, Vol. 34, United Nations High Commission for Refugees (UNHCR), Geneva.

Bogardi, J. and Warner, K. (2008) 'Here comes the flood', Nature Reports Climate Change [online] http://www.nature.com/climate/2009/0901/full/climate.2008.138.html (accessed 30 April 2014).

Boncour, P. and Burson, B. (2010) 'South pacific region: policy perspectives', in Burson, B. (Eds.): Climate Change and Migration: South Pacific Perspectives, pp.5-28, Institute for Policy Studies, Wellington.

Bronen, R. (2013) Climate-Induced Displacement of Alaska Native Communities, Brookings-LSE: Project on Internal Displacement [online] http://www.brookings.edu/ /media/research/files/ papers/2013/1/30\%20arctic\%20alaska\%20bronen/30\%20climate\%20alaska\%20bronen $\% 20$ pa per.pdf (accessed 30 April 2014).

Brown, O. (2008) Migration and Climate Change, Migration Research Series, No. 31, International Organisation for Migration (IOM), Geneva.

Burson, B. (2010) 'Protecting the rights of people displaced by climate change: global issues and regional perspectives', in Burson, B. (Eds.): Climate Change and Migration: South Pacific Perspectives, pp.159-180, Institute of Policy Studies, Wellington.

Byravan, S. and Rajan, R.C. (2010) 'The ethical implications of sea-level rise due to climate change', Ethics and International Affairs, Vol. 24, No. 3, pp.239-260.

Campbell, J. (2010) 'Climate change and population movement in pacific island countries', in Burson, B. (Eds.): Climate Change and Migration: South Pacific Perspectives, pp.29-50, Institute of Policy Studies, Wellington.

Church, J.A., Clark, P.U., Cazenave, A., Gregory, J.M., Jevrejeva, S., Levermann, A., Merrifield, M.A., Mlne, G., Nerem, R.S., Dunn, P.P., Payne, A.J., Pfeffer, W.T., Stammer, D. and Unnikrishnana, A.S. (2013) 'Sea level change', in Climate Change 2013: Sea Level Change, Climate Change 2013: The Physical Science Basis, Contribution of Working Group I to the Fifth Assessment Report of the Intergovernmental Panel on Climate Change [Stocker, T.F., Qin, D., Plattner, G-K., Tignor, M., Allen, S.K., Boschung, J., Nauels, A., Xia, Y., Bex, V. and Midgley, P.M. (Eds.)]. Cambridge University Press, Cambridge, UK and New York, NY, USA.

Cochran, P., Huntington, O.H., Pungowiyi, C., Tom, S., Chapin, F.S., Huntington, H.P., Maynard, N.G. and Trainor, S.F. (2013) 'Indigenous frameworks for observing and responding to climate change in Alaska', Special Issue Climatic Change, Vol. 12, No. 3, pp.557-567.

Collins, M., Knutti, R., Arblaster, J., Dufresne, J-L., Fichefet, T., Friedlingstein, P., Gao, X., Gutowski, W.J., Johns, T., Krinner, G., Shongwe, M., Tebaldi, C., Weaver, A.J. and Wehner, M. (2013) 'Long-term climate change: projections, commitments and irreversibility', Climate Change 2013: The Physical Science Basis, Contribution of Working Group I to the Fifth Assessment Report of the Intergovernmental Panel on Climate Change [Stocker, T.F., Qin, D., Plattner, G-K., Tignor, M., Allen, S.K., Boschung, J., Nauels, A., Xia, Y., Bex, V. and Midgley, P.M. (Eds.)], Cambridge University Press, Cambridge, UK and New York, NY, USA. 
Crawford, J. (2006) The Creation of States in International Law, 2nd ed., Oxford University Press, Oxford.

Crump, J. (2008) 'Many strong voices: climate change and equity in the Arctic', Indigenous Affairs, Vols. 1-2, pp.24-33.

Dasgupta, S., Laplante, B., Meisner, C., Wheeler, C. and Yan, J. (2007) The Impact of Sea Level Rise on Developing Countries: A Comparative Analysis, World Bank Policy Research Working Paper, No. 4136 [online] http://www-wds.worldbank.org/external/default/ WDSContentServer/IW3P/IB/2007/02/09/000016406_20070209161430/Rendered/PDF/wps4 136.pdf (accessed 30 April 2014).

FitzGerald, D.M., Fenster, M.S., Argow, B.A. and Buynevich, I.V. (2008) 'Coastal impacts due to sea-level rise', Annual Review of Earth and Planetary Sciences, Vol. 36, pp.601-647.

Forbes, D.L. (Eds.) (2011) State of the Arctic Coast 2010 - Scientific Review and Outlook, International Permafrost Association, Germany.

Ford, J. (2009) 'Dangerous climate change and the importance of adaptation for the Arctic's Inuit population', Environmental Research Letters, No. 4, pp.1-9.

Foresight: Migration and Global Environmental Change (2011) Final Project Report, The Government Office for Science, London.

Frankhauser, S. (2009) 'The range of global estimates', in Parry, M.L., Arnell, N., Berry, P., Dodman, D., Frankhauser, S., Hope, C., Kovats, K., Nicholls, R., Satterthwaite, D., Tiffin, R. and Nicholls, T. (Eds.): Assessing the Costs of Adaptation to Climate Change: A Review of the UNFCCC and Other Recent Estimates, International Institute for Environment and Development (IIED), London.

Government Accountability Office (GAO) (2009) Alaska Native Villages: Limited Progress has been Made on Relocating Villages Threatened by Flooding and Erosion, Report to Congressional Requesters, GAO-09-551.

Government of Fiji (2014) Fiji Supports Kiribati on Sea Level Rise [online] http://www.climate.gov.ki/2014/02/20/fiji-supports-kiribati-on-sea-level-rise/ (accessed 10 March 2014).

Government of Kiribati (2007) National Adaptation Program of Action (NAPA), Ministry of Environment, Land, and Agricultural Development [online] http://unfccc.int/resource/docs/ napa/kir01.pdf (accessed 30 April 2014).

Government of Kiribati (2013) Relocation, Office of the President of Republic of Kiribati [online] http://www.climate.gov.ki/category/action/relocation/ (accessed 30 April 2014).

Gunewardena, N., Schuller, M. and de Waal, A. (2008) Capitalizing On Catastrophe: Neoliberal Strategies in Disaster Reconstruction, Altamira Press, Lanham.

Hinzman, L.D., Bettez, N.D., Bolton, W.R., Chapin, F.S., Dyurgerov, M.B., Fastie, C.L., Griffith, B., Hollister, R.D., Hope, A., Huntington, H.P., Jensen, A.M. and Jia, G.J. (2005) 'Evidence and implications of recent climate change in Northern Alaska and other Arctic regions', Climatic Change, Vol. 72, pp.251-298.

Kälin, W. (2010) 'Conceptualising climate-induced displacement', in McAdam, J. (Eds.): Climate Change and Displacement: Multidisciplinary Perspectives, pp.81-103, Hart Publishing, Oxford and Portland.

Kattsov, V. and Källén, E. (2005) 'Chapter 4: future climate change: modeling and scenarios for the Arctic', Arctic Climate Impact Assessment, pp.99-150.

Kiribati Climate Change (n.d.) Relocation [online] http://www.climate.gov.ki/category/ action/relocation/ (accessed 12 January 2013).

Krupnik, I. and Jolly, D. (Eds.) (2002) The Earth is Faster Now: Indigenous Observations of Arctic Environmental Change, Arctic Research Consortium of the United States, Fairbanks.

Langan, B. (2013) 'Kiribati: a nation going under', The Global Mail [online] http://www.theglobalmail.org/feature/kiribati-a-nation-going-under/590/ (accessed 30 April 2014). 
Larsen, J.N., Anisimov, O.A., Constable, A., Hollowed, A., Maynard, N., Prestrud, P., Prowse, T. and Stone, J. (2014) 'Chapter 28: polar regions', Climate Change 2014: Impacts, Adaptation and Vulnerability, Contribution of Working Group II to the Fifth Assessment Report of the Intergovernmental Panel on Climate Change, Cambridge University Press, Cambridge and New York.

Larsen, P.H., Goldsmith, S., Smith, O., Wilson, M., Strzepek, K., Chinowsky, P. and Saylor, B. (2008) 'Estimating future costs for Alaska public infrastructure at risk from climate change', Global Environmental Change, Vol. 18, No. 3, pp.442-457.

Locke, J. (2009) 'Climate change-induced migration in the Pacific region: sudden crisis and long-term developments', The Geographic Journal, Vol. 175, No. 3, pp.171-180.

Loughry, M. and McAdam, J. (2008) 'Kiribati - relocation and adaptation', Climate Change and Development, Forced Migration Review, Vol. 31, pp.51-52.

Marino, E. (2009) 'Immanent threats, impossible moves, and unlikely prestige: understanding the struggle for local control as a means towards sustainability', in Oliver-Smith, A. and Shen, X. (Eds.): Linking Environmental Change, Migration and Social Vulnerability, pp.42-50, No. 12, United Nations University Institute for Environment and Human Security (UNU-EHS) Publication Series, Bonn.

McAdam, J. and Loughry, M. (2009) 'We aren't refugees', Inside Story: Current Affairs and Culture from Australia and Beyond [online] http://inside.org.au/we-arent-refugees/ (accessed 30 April 2014).

Montreux, C. and Barnett, J. (2009) 'Climate change, migration and adaptation in Funafuti, Tuvalu', Global Environmental Change, Vol. 19, pp.105-112.

Morrissey, J. and Oliver-Smith, A. (2013) 'Perspectives on non-economic loss and damage: understanding values at risk from climate change', Loss and Damage Series, United Nations University Institute for Environment and Human Security, Bonn.

Newland, K. (2011) Climate Change and Migration Dynamics, Migration Policy Institute, Washington, DC.

Nicholls, R. and Cazenave, A. (2010) 'Review: sea-level rise and its impact on coastal zones', Science, Vol. 328, No. 5985, pp.1517-1520.

Nicholls, R.J. and Tol, R.S.J. (2006) 'Impacts and responses to sea-level rise: a global analysis of SREX scenarios over the twenty-first century', Philosophical Transactions of the Royal Society, Vol. 364, pp.1073-1095.

Nicholls, R.J., Marinova, N., Lowe, J.A., Brown, S., Vellinga, P., de Gusmão, D., Hinkel, J. and Tol, R.S.J. (2011) 'Sea-level rise and its possible impacts given a 'beyond 4 degrees celsius world' in the twenty-first century', Philosophical Transactions of the Royal Society, Vol. 369, No. 1934, pp.161-181.

Norton, D. (2002) 'Coastal sea ice watch: Private confessions of a convert to indigenous knowledge', in Krupnik, I. and Jolly, D. (Eds.): The Earth is Faster Now: Indigenous Observations of Arctic Environmental Change, pp.126-155, Arctic Research Consortium of the United States, Fairbanks.

Nuttall, M., Berkes, F., Forbes, B., Kofinas, G., Vlassova, T. and Wenzel, G. (2005) 'Hunting, herding, fishing and gathering: indigenous peoples and renewable resource use in the Arctic', in Symon, C., Arris, L. and Heal, B. (Eds.): Arctic Climate Impacts Assessment (ACIA), pp.649-690, Cambridge University Press, Cambridge.

Parkinson, A.J. and Butler, J.C. (2005) 'Potential impacts of climate change on infectious diseases in the Arctic', International Journal of Circumpolar Health, Vol. 64, No. 5, pp.478-486.

Pelling, M. and Uitto, J.I. (2001) 'Small Island Developing States: natural disaster vulnerability and global change', Environmental Hazards, Vol. 3, pp.49-62.

Radio New Zealand International (2009) Kiribati President Says Copenhagen failure Shows Process Flawed [online] http://www.rnzi.com/pages/news.php?op=read\&id=51063 (accessed 30 April 2014). 
Ramesh, R. (2009) 'Maldives ministers prepares for underwater meetings', The Guardian [online] http://www.guardian.co.uk/world/2009/oct/07/maldives-underwater-cabinet-meeting (accessed 30 April 2014).

Schweitzer, P. and Marino, E. (2006) Collocation Cultural Impact Assessment: Coastal Erosion Protection and Community Relocation, Shishmaref Alaska, Tetra Tech Inc., Washington, DC.

Serreze, M. and Francis, J. (2006) 'The Arctic on the fast track of change', Weather, Vol. 61, No. 3, pp.65-69.

Shearer, C. (2012) 'The political ecology of climate adaptation assistance: Alaska natives, displacement, and relocation', Journal of Political Ecology, Vol. 19, pp.174-183.

Strategic National Policy Unit, Office of The Beretitenti, Kiribati (2012) 'Prepare I-Kiribati people for eventual relocation through vocational training offerings and labour mobility', United Nations Framework Convention on Climate Change (UNFCCC) [online]

http://unfccc.int/files/adaptation/cancun_adaptation_framework/loss_and_damage/application/ pdf/info_sheet_new_relocation_kiribati.pdf (accessed 30 April 2014).

Tacoli, C. (2009) 'Crisis or adaptation? Migration and climate change in a context of high mobility', Environment and Urbanisation, Vol. 21, No. 2, pp.513-525.

Thorpe, N., Eyegetok, S., Hakongak, N. and the Kitikmeot Elders (2002) 'Nowadays it is not the same: Inuit Qaujimajatuqangit, climate and caribou in the Kitikmeot Region of Nunavut, Canada', in Krupnik, I. and Jolly, D. (Eds.): The Earth is Faster Now: Indigenous Observations of Arctic Environmental Change, pp.198-239, Arctic Research Consortium of the United States, Fairbanks.

Tol, R. (2002) 'Estimates of the damage costs of climate change. Part 1: benchmark estimates', Environmental and Resource Economics, Vol. 21, No. 1, pp.47-73.

Unites States Army Corps of Engineers (USACE) (2009) Study Findings and Technical Report: Alaska Baseline Erosion Assessment, USACE, Alaska.

Verheyen, R. (2012) Tackling Loss and Damage: A New Role for the Climate Regime?, Germanwatch, Bonn.

Warner, K., Afifi, T., Kälin, W., Leckie, S., Ferris, Beth, Martin, S.F. and Wrathall, D. (2013) Changing Climate, Moving People: Framing Migration, Displacement and Planned Relocation, Policy Brief No. 8, United Nations University Institute for Environment and Human Security (UNU-EHS) Publication Series, Bonn.

Warner, K., van der Geest, K., Kreft, S., Huq, S., Harmeling, S., Kusters, K. and de Sherbinin, A. (2012) 'Evidence from the frontlines of climate change: loss and damage to communities despite coping and adaptation', Loss and Damage in Vulnerable Countries Initiative, Policy Report No. 9, United Nations University Institute for Environment and Human Security (UNU-EHS) Publication Series, Bonn.

Watters, R.F. (2008) Journeys Towards Progress: Essays of a Geographer on Development and Change in Oceania, Victoria University Press, Wellington.

Webb, A.P. and Kench, P.S. (2010) 'The dynamic response of reef islands to sea level rise: evidence from multi-decadal analysis of island change in the central pacific', Global and Planetary Change, Vol. 72, pp.234-246.

Wong, P.P., Losadao, I.J., Gattuso, J-P, Hinkel, J., Khattabi, A., McInnes, K., Saito, Y. and Sallenger, A. (2014) 'Chapter 5: coastal systems and low-lying areas', Climate Change 2014: Impacts, Adaptation and Vulnerability, Contribution of Working Group II to the Fifth Assessment Report of the Intergovernmental Panel on Climate Change, Cambridge University Press, Cambridge and New York.

World Bank (2011a) Implementation, Completion and Results Report on a Global Environmental Facility Grant to the Republic of Kiribati for an Adaptation Project - Implementation Phase (KAP II) [online] http://www-wds.worldbank.org/external/default/WDSContentServer/WDSP/ IB/2012/03/16/000356161_20120316010427/Rendered/PDF/ICR17510P089320C0disclosed0 30140120.pdf (accessed 30 April 2014). 
World Bank (2011b) Project Appraisal Document on a Proposed Grant from the Global Environment Facility Least Developed Country Fund in the Amount of US\$3.0 million to the Republic of Kiribati for the Kiribati Adaptation Programme - Phase III [online] http://wwwwds.worldbank.org/external/default/WDSContentServer/WDSP/IB/2011/08/31/000370910 20 110831153511/Rendered/PDF/638740PAD00P110e0only0900BOX361536B.pdf (accessed 30 April 2014).

Wyett, K. (2014) 'Escaping a rising tide: sea level rise and migration in Kiribati', Asia and the Pacific Policy Studies, Vol. 1, No. 1, pp.171-185.

Zetter, R. (2007) 'More labels, fewer refugees: making and remaking the refugee label in an era of globalization', Journal of Refugee Studies, Vol. 20, No. 2, pp.172-192. 